\title{
Una antologia marquiana a la Barcelona del tercer quart del segle XV
}

\author{
[An Ausiàs March anthology in Barcelona \\ by the third quarter of the fifteenth century]
}

\author{
FranCESC J. GómeZ \\ Universitat Autònoma de Barcelona \\ francescjosep.gomez@uab.cat
}

Resum: Aquest article estudia l'estreta relació dels testimonis barcelonins AILM de la poesia de March des d'una perspectiva codicològica i ecdòtica. Una anàlisi d'aquesta mena fa pensar que la majoria dels poemes compartits pels testimonis $A L$ davallen d'un antecedent comú, consistent en una antologia conforme a l'ordre establert per Pagès a partir dels testimonis monogràfics de l'obra de March. Aquesta antologia, emparentada amb el cançoner de Nova York $(N)$, no fou l'única font dels testimonis $A L M$, que presenten altres indicis de relació amb el cançoner de Saragossa $(H)$.

Paraules clau: Ausiàs March, crítica textual, cançoner d'obres enamorades, cançoner de l'Ateneu, cançoner $L$

Aвstract: This essay examines the close relation between the Barcelona witnesses AILM of March's poetry from both a codicological and ecdotic perspective. Such an analysis leads to suggest that most of the poems present in both manuscripts $A L$ go back to a common archetype, consisting in an anthology in the order established by Pagès according to the monographic manuscripts of March's works. This anthology, related to the New York manuscript $N$, was not the only source of $A L M$, in which other particular relations with the Zaragoza manuscript $H$ can also be detected.

KEYwords: Ausiàs March, ecdotic, cançoner d'obres enamorades, cançoner de l'Ateneu, cançoner $L$

Recepció: 05/09/2017. Acceptació: 27/09/2017. Publicació: I 5/I2/20I7

REVISTA VALENCIANA DE FILOLOGIA / I (20I7) p. 6I-94/ISSN 0556-705X DOI I0.28939/RVF.VIII.2I 
Tots els estudis de conjunt de la tradició textual d'Ausiàs March han remarcat l'existència d'un estret parentiu entre els testimonis miscel-lanis ALM (cançoners JLN segons les sigles de Jaume Massó), no solament pel que fa a variants textuals sinó també a la tria de poemes que transmeten (Pagès 1912-1914: I, 118-119; Archer 1997: II, 26), sense determinar, però, fins a quin punt la tria i la distribució d'aquests cançoners fou deguda al criteri particular de cada copista (Beltran 2006b: 113-115, 121-123) o bé a un indiscutible antecedent comú. Per mirar de precisar aquest punt, proposo tot seguit de parar atenció a les particularitats dispositives de cada cançoner i al context en què foren produïts, així com a altres qüestions concomitants, com ara la posició del grup dins el conjunt de la tradició o la possible confluència de branques textuals diverses, atès que la discrepància entre els stemmata de Pagès (1912-1914: I, 147 i làmina III) i Archer (1997: II, 33) és absoluta en aquest cas.

\section{Ausiàs March en els cançoners JKLN (March: AILM)}

El cançoner L (March: L; Barcelona, Biblioteca de Catalunya, ms. 9), darrerament descrit per Vicenç Beltran (2006b: 172-174) i Francisco J. Rodríguez Risquete (2003: LXXXI-LXXXIV), es conserva en un estat molt fragmentari per la pèrdua de folis i quaderns sencers, cosa que en dificulta l'estudi i la datació (c. 1460/1470). És auster però elegant, potser la còpia en net d'un cançoner privat. Consta de 153 folis de paper in quarto $(220 \times 145 \mathrm{~mm})$ distribuits en set plecs enquadernats modernament en un ordre incorrecte. Segons la hipòtesi de reconstrucció de Rodríguez Risquete, l'estructura original del cançoner consistia en tres blocs successius:

* Projecte FFI 2014-53050-C5-4-P finançat pel Ministeri d'Economia i Competitivitat (2015-2018).

REVISTA VALENCIANA DE FILOLOGIA / I (20I7) p. 6I-94 FRANCESC J. GÓMEZ

Una antologia marquiana a la Barcelona del tercer quart del segle XV / 62 
I. Plec 1 (f. 1-23) + llacuna d'un plec o més + plecs 4-6 (f. 78-132)

+ llacuna d'un plec o més. Miscel-lània de poetes dels segles XIV-XV.

D’Ausiàs March inclou els poemes 6 (f. 14r-15v), 7 (f. 106r-107v) i 1-2

amb correccions (f. $117 \mathrm{v}-119 \mathrm{r}$ ).

II. Plecs 2-3 (f. 24-77) i 7 inici (f. 133-137r). Antologia de Joan

Berenguer de Masdovelles (els darrers folis del plec 7, després de 137v, restaren en blanc).

III. Plec 7 cont. (f. 137v-153v) + llacuna d'un plec o més. Antologia d'Ausiàs March, copiada per la mateixa mà en un moment posterior.

Poemes de March: 3, 5, 9, 11, 14, 16, 17, 19, 21, 27, 28, 29, 33, 34, 36, 37, 44, 45 (truncat: manquen els v. 41-100).

Avui, doncs, el cançoner $L$ conté només 22 composicions d'Ausiàs March, però és probable que n'hagués contingudes força més. Els poemes 6 , 7, 1 i 2 hi apareixen dins el primer bloc, una miscel-lània de poetes dels segles XIV-XV, però no podem assegurar que s'hi haguessin afegit a posteriori, sinó més aviat al contrari, especialment la cançó 6 . Ara bé, si el cançoner es tractés, com sembla, d'una còpia en net, fóra possible que aquests quatre poemes s'haguessin afegit a la miscel-lània en el seu antígraf $\left(L^{\prime}\right)$. Els altres poemes marquians constitueixen una secció monogràfica, aparentment afegida a posteriori, rigorosament conforme a l'ordre canònic, tot i que saltuària i truncada per la pèrdua d'un nombre indeterminat de quaderns.

El cançoner N (March: M; Barcelona, Biblioteca de l'Ateneu, ms. 1) consta de 236 folis de paper, també in quarto $(212 \times 142 \mathrm{~mm})$, i d'aparença descurada. Segons l'excel·lent estudi de Francisco J. Rodríguez Risquete (2010), és un registre poètic d'ús privat, constituiit progressivament a partir de $1461 \mathrm{amb}$ materials compartits amb els cançoners JKL (una antologia de Joan Berenguer de Masdovelles i una miscel-lània de poetes dels segles XIV-XV) i la incorporació d'altres elements: dos quaderns heterogenis $(4-5)$ procedents de la cort literària de Carles de Viana; successives ampliacions amb obres relacionades amb la tradició del cançoner de Saragossa $P$ (March: $H$ ) o rigorosament contemporànies

REVISTA VALENCIANA DE FILOLOGIA / I (20I7) p. 6I-94

FRANCESC J. GÓMEZ

Una antologia marquiana a la Barcelona del tercer quart del segle XV / 63 
(quaderns 10-12); un darrer quadern (13) afegit als anys vuitanta, i, finalment, la còpia d'unes cobles de sant Magí compostes a Santa Coloma de Queralt el 1525 (f. 55r). Les rúbriques de les obres de Joan Fogassot solen detallar-ne les circumstàncies de composició, i una nota als v. 27-30 de la seva cançó de croada «Dels doctes fels» ho fa en primera persona (f. 21r), cosa que convida a relacionar el cançoner amb el cercle íntim d'aquest poeta i notari, malgrat les reserves expressades per Rodríguez Risquete (2010: 456-457 n. 35).

El cançoner de l'Ateneu no conté una secció marquiana com l'afegida a $L$, sinó només sis obres —novament les cançons 6 i 7, més el maldit 42 i les esparses 29, 80 i 81-, ubicades en llocs no gaire destacats, amb un cert criteri genèric. El copista principal $(a)$ i possessor del cançoner, responsable únic dels quaderns 1-3, 6-9 i 11-12, ha copiat la cançó 6 (f. 73r-v) en un espai en blanc de la secció més heterogènia (quaderns 4-5), deguda almenys a dues mans precedents ( $b$ i $c$ ), després d'un poema anònim en decasíl labs. Les esparses 80 (f. 146v), 29 (f. 147r) i 81 (f. 147r) es copien seguides en el quadern 8, dins una secció d'esparses i composicions breus de poetes de mitjan Xv (f. 145r-148v) estretament emparentada amb JKL. El maldit 42 (f. 155r-v) s'inclou, així mateix, en el quadern 9 entre maldits i cançons amoroses i morals també de poetes de mitjan Xv. La cançó 7 (f. 184r-185r) ha estat copiada en el quadern 10, iniciat aparentment per una altra mà $(d)$ i constituït per una miscel-lània de textos amorosos antics i moderns d'enfocament moralitzant.

El cançoner J o Cançoner d'obres enamorades (March: A; París, Bibliothèque Nationale de France, ms. esp. 225), estudiat per Vicenç Beltran (2006b: 91-126) i Rodríguez Risquete (2003: LXXIX-LXXXI), consta de 269 folis de paper in folio $(288 \times 217 \mathrm{~mm})$, amb pretensions de cançoner públic, distribuïts en disset plecs (I-II + 1-15), segons l'estructura següent:

I. Plecs I-II (f. A-T):

a) Privilegi de la Gaia Ciència de Ferran I (f. Ar-Bv) [afegits posteriors: Romanç sobre la presó o detenció de don Carles, príncep de Viana i primogènit d'Aragó (f. Er-Iv) i Liberació del primogènit (f. Iv-Jv) de Joan Fogassot; Complanta sobre la mort del primogènit

REVISTA VALENCIANA DE FILOLOGIA / I (20I7) p. 6I-94 FRANCESC J. GÓMEZ

Una antologia marquiana a la Barcelona del tercer quart del segle XV/ 64 
d'Aragó don Carles (f. Kr-Lr) de Guillem Gibert];

b) Taula (f. $\mathrm{Mr}-\mathrm{Pv}$ ) [afegits posteriors: «O banch segur» [R 99.6)]

(f. Qr-Rv), al lloctinent Joan; «Al Rey Jhesús» [R 99.2] (f. Sr-Tv) de Pero Martines].

II. Plecs 1-4 (ff. 1-16, 17-32, 33-48, 49-60):

a) Bernat Hug de Rocabertí, Glòria d'amor (f. 1r-24v);

b) Ausiàs March, secció I (f. 25r-55v) amb tres poemes intercalats de Jaume March i un fragment de la segona balada de Lluís de Vila-rasa atribuïda a Ausiàs March;

c) miscel·lània I (f. 56r-60v), amb cançons de Pere Torroella (o atribuïdes) i de Figueres.

III. Plecs 5-10 (f. 61-76, 77-98, 99-116, 117-134, 135-146, 147-164):

a) Joan Berenguer de Masdovelles (f. 61-93);

b) miscel·lània II (f. 93v-164) de poetes dels segles XIV-XV, interrompuda per una secció de cobles esparses (f. 103r-109v). Fora d'aquesta secció inclou les esparses 83 i 82 (f. 150v i 157v) d'Ausiàs March.

IV. Plecs 11-15 (f. 165-246):

a) Requesta d'amor de madama sens mercí, feta per mestre [Alain Chartier; una segona mà anota que és trad. cat. de Francesc Oliver] (f. 165r-177r);

b) Ausiàs March, secció II (f. 177v-209v);

c) miscel-lània III (f. 210r-245) de poetes de mitjan Xv [textos afegits: amb data de 7 de desembre de 1475, Joan Ramon Ferrer, mantenidor del consistori de la Gaia Ciència, insta Joan Fogassot a emetre sentència sobre una tençó moguda per Ricard contra Pere Pau Saguda, defensor dels vidus (f. 247r); sentència de Joan Fogassot (f. 246r-v)].

La identificació del poeta "mossèn Avinyó» (f. 215v-221v) amb el tarragoní Lluís d'Avinyó, uixer d'armes de Carles de Viana, adobat a cavaller pel mateix príncep el 24 de juny de 1461 (Galí, Ramos \& Torró 2010), ${ }^{1}$ permet de

1 Beltran (2006b: 103 n. 53) havia arribat a considerar aquesta possibilitat d'identificació, però sense

REVISTA VALENCIANA DE FILOLOGIA / I (20I7) p. 6I-94

FRANCESC J. GÓMEZ

Una antologia marquiana a la Barcelona del tercer quart del segle XV / 65 
datar el cançoner $J$ en una data necessàriament posterior, tot i que potser no gaire. Vicenç Beltran havia proposat de datar-lo entre 1459 i 1461 considerant com a argument ante quem els poemes de Joan Fogassot (f. E-J) i de Guillem Gibert (f. K-L) copiats en els folis que havien restat en blanc en el primer plec, i com a argument post quem les poesies d'Antoni Vallmanya que clouen el cançoner, datades explícitament (1457-1459) amb unes notes circumstanciades, i alguna en primera persona (f. 244v). ${ }^{2}$ La còpia del Privilegi inicial (f. A-B) i els afegitons finals - la instància de Joan Ramon Ferrer i la sentència de Joan Fogassot (f. 246-247) — fan pensar que pels volts de 1475 fou posseït per algú proper al Consistori de la Gaia Ciència de Barcelona (M. Cabré 2002).

Gràcies, d'altra banda, a la possibilitat de datar el 1451 sengles poemes de Masdovelles (f. 82r) i de Francí Guerau (f. 100r), el 1453 l'elogi «Rei virtuós» de Joan Fogassot (f. 140v) i el 1457 l'únic poema conegut de Ferran d'Ayerbe (f. 158r), Beltran (2006b: 112) proposava de situar entre els anys 1450-1459

confirmar-la ni treure'n conclusions. Lluís d'Avinyó, mort abans del 8 de juliol de 1477, i actiu com a poeta en català i castellà almenys fins al 1473, fou també autor d'una crònica de Catalunya avui perduda. Documentat com a donzell des del 1435, estigué al servei del príncep Carles i relacionat amb Pere Torroella i el cercle poètic reflectit al Cançoner del marquès de Barberà; durant la guerra civil catalana formà part del cercle reialista del Cancionero de Vindel, del qual s'ha argumentat que podria haver estat no sols possessor sinó també compilador fins poc abans de la seva mort (setembre de 1476 / juliol de 1477), així com potser copià i féu copiar el cançoner català $\mathrm{O}_{2}$, testimoni $N$ de la poesia marquiana (Ramos, Rodríguez Risquete \& Torró 2014). La poesia d'Avinyó, conservada en els cançoners JK i en el Cancionero de Vindel, és imitadora de Jordi de Sant Jordi, Martí Garcia, Ausiàs March, Pere Torroella, Juan de Mena i Petrarca.

2 Beltran (2006b: 109-111, 123-126 i 173) vincula els cançoners JKLN amb un cenacle de poetes barcelonins integrat pels notaris Antoni Vallmanya i Joan Fogassot, en estreta relació amb Joan Berenguer de Masdovelles i la cort reial. Joan de Navarra esdevingué lloctinent del Magnànim a Catalunya el 31 de maig de 1454, així com ho era al Regne de València d'ençà del 1436: sembla una dada rellevant per a comprendre la difusió barcelonina del corpus marquià i dels primers ausiasmarquistes cortesans, com Lluís de Vila-rasa o Bernat Hug de Rocabertí. Arran d'aquesta nova lloctinença, Joan de Navarra passà llargues temporades a Barcelona, com ara aquella estada d'un any (març de 1455 - febrer de 1456) durant la qual se celebrà el famós «Pas du pin aux pommes d'or». En aquestes mateixes dates, o si més no durant aquest període de lloctinença (1454-1458), cal datar el debat poètic entre Fogassot i Vallmanya, que apel-laren a la sentència de Joan com a lloctinent reial (Marfany 2007), i és també en aquestes dates que Fogassot i Vallmanya entren al servei de la cort de Joan, com ha documentat Rodríguez Risquete (2003: LVI). Sembla, doncs, que la connexió cortesana té molt a veure, no solament amb la producció poètica de Vallmanya i Fogassot, sinó també amb els materials que conflueixen en aquest grup de cançoners barcelonins.

REVISTA VALENCIANA DE FILOLOGIA / I (20I7) p. 6I-94

FRANCESC J. GÓMEZ

Una antologia marquiana a la Barcelona del tercer quart del segle XV / 66 
la confecció material del cançoner. Aquesta proposta, però, topa d'entrada amb l'evidència que el programa compilador del cançoner $J$ fou concebut en una data posterior a la composició de les dues grans obres que encapçalen les dues seccions marquianes: la Glòria d'amor de fra Bernat Hug de Rocabertí, que inaugura el cançoner, i la traducció catalana de la Belle dame sans merci d'Alain Chartier, dues obres que exerciren una fortíssima influència sobre les cançons d'Antoni Vallmanya (1457-1459), com ha demostrat Marta Marfany (2007 i 2010), i que es degueren difondre a Barcelona cap a 1455/1456 o poc després. A més a més, però, cal observar que les dates enumerades per Beltran es refereixen només als materials que integren el bloc III del cançoner, en gran part compartits amb els cançoners $L$ i $N$. Val a dir que el mateix Beltran (2006a: 90-94; 2006b: $110 \mathrm{n} .75$ ) ha constatat que $J$ i $L$ comparteixen un mateix model antològic per a les obres de Joan Berenguer de Masdovelles.

Combinant, tanmateix, els suggeriments de Beltran i de Rodríguez Risquete, podem considerar que cap al final de la dècada dels cinquanta es confeccionà, no pas el còdex $J$, sinó el nucli bàsic dels dos cançoners que conflueixen en els programes compiladors, d'altra banda ben diferents, de JLN: una miscel-lània de poetes dels segles XIV-xv i una antologia de Joan Berenguer de Masdovelles, a les quals s'incorporà l'antologia d'Ausiàs March que sembla afegida al final de $L$, i que en $J$ ocupa un lloc destacat, protagonitzant dues seccions inaugurades pels grans poemes narratius de Rocabertí i Chartier (indico en negreta els poemes de March testimoniats en $L$ ):

Bloc II: Rocabertí, Glòria d'amor (f. 1r-24v) + secció I d'Ausiàs March (f. 25r-55v): 75, 17, 16, 14, 11, 9, 100 [Jaume March, «Dos són los alts» (f. 33r-v)] 99, 98, 97-94, 92 [Jaume March, «Un sobrespler» (f. 44r-v)] 45, 55, 54, 3 [Lluís de Vila-rasa, Balada II («Sobresdamor»), v. 9-24 (om. primera cobla), atribuïda a Ausiàs March (f. 48r); Jaume March, «Las, treballat» (f. 48r-v)] 1, 2, 3, 4, 5, 6, 7, 93 + Complanta, s. n. [Pere Torroella,] «Delit no·m ve» (f. 56r) ...

Bloc III: ... 83 (f. 150v) ... 82 (f. 157v) ...

REVISTA VALENCIANA DE FILOLOGIA / I (20I7) p. 6I-94

FRANCESC J. GÓMEZ

Una antologia marquiana a la Barcelona del tercer quart del segle XV / 67 
Bloc IV: Madama sens mercí, s. n. (f. 165r-177r) + secció II d'Ausiàs March (f. 177v-209v): 87, 51, 83, 46, 44, 37, 36, 34, 33, 28, 27, 21, 19, 29, 80, 76, 78, 81, 88, 89, 90, 23 [af. esparsa de Vallmanya, «Los [ms. Vós] d'amar fals» (f. 195r)], 38, 49 [af. esparsa de Vallmanya, «No·m plau lo tall» (f. 196v)], 50, 53, 56, 58, 69, 71, 64, 77, 13 [af. esparsa de Lleonard de Sos, «Cell qui mal diu» (f. 204r)] 39, 18, 42, 32 (v. 1-8 repetits al f. 209v) [af. esparsa de Pere d'Abella, «Pux així·t plau» (f. 207r)], 30 (v. 1-16) + 26 (v. 25-60) [com una sola obra], 24, 10, 31...

La posició d'Ausiàs March és encara més prominent en el cançoner $K$ (March: I; Barcelona, Biblioteca de Catalunya, ms. 10), un apògraf de $J$ reordenat segons un programa compilador molt més clar (Beltran 2006b: 126144), amb seccions dedicades a Ausiàs March, Joan Berenguer de Masdovelles, mossèn Avinyó (mutilada), Lleonard de Sos i Antoni Vallmanya - però no pas a Jordi de Sant Jordi o Pere Torroella, entre d'altres (Beltran 2006b: 140-142). Actualment consta de 212 folis de paper in folio $(275 \times 215 \mathrm{~mm})$ i s'obre amb el v. 860 de la Glòria d'amor de Rocabertí (f. 14-10v), acèfala per la pèrdua dels catorze primers folis del còdex. Tot seguit, sense canvi de pàgina, es copia la traducció catalana del poema narratiu de Chartier (f. 10v-23r), atribuït a Ausiàs March per un rubricador amb lletra humanística rodona ( $O$ Obra feta per Mossèn Auziàs March, coronada»); una altra mà més cursiva hi copia a sota el títol de $J$ (Beltran 2006b: 132-133). Després es copien, seguides l'una rere l'altra, les dues seccions marquianes de $J$, incloent-hi les obres intercalades d'altres autors i les falses atribucions (f. $23 \mathrm{v}-79 \mathrm{v}$ ), però no pas les dues esparses (83 i 82) del bloc III, mentre que les esparses de Vallmanya afegides en la secció II de $J$ s'agrupen en $K$ amb l'obra d'aquest poeta. Després de March continua la miscel-lània I de $J$, encapçalada per Torroella, Figueres i Joan Berenguer de Masdovelles, però a partir d'aquí el copista aplega també totes les obres d'aquest poeta (Beltran 2006b: 135); la tasca de reordenació prossegueix fins al darrer autor, Antoni Vallmanya, afegint-hi la cançó "Junt és lo temps fer de ma dolor crida» que manca en $J$. A més de la mutilació inicial, el manuscrit presenta una llacuna de vint folis (f. 157-176) que, segons el càlcul de Beltran

REVISTA VALENCIANA DE FILOLOGIA / I (20I7) p. 6I-94 FRANCESC J. GÓMEZ

Una antologia marquiana a la Barcelona del tercer quart del segle XV / 68 
(2006b: 138-139), hauria pogut contenir molts dels poemes de la miscel-lània d'autors dels segles XIV-XV que no s'havien recol-locat en alguna de les seccions d'autor conservades. L'esparsa 82, no reagrupada amb les obres de March, podria haver-s'hi perdut, mentre que la 83 ja hi era, repetida, en la secció II de $J$.

Totes les obres d'Ausiàs March han estat numerades en $J$ i $K$ amb xifres aràbigues per una mateixa mà posterior (Pagès 1912-1914: I, 45-46) o per dues de molt semblants (Beltran 2006b: 133 i 143). D'acord amb Pagès i no pas amb Beltran, em sembla evident que la numeració s'ha fet primerament en $K$ i s'ha reproduït després en $J$, corregint-ne alguns errors. ${ }^{3}$ En tot cas, és evident que $J$ i $K$ restaren molt a prop l'un de l'altre durant molt de temps, potser a la mateixa biblioteca on van ésser copiats (Beltran 2006b: 144).

Mentre que $K$ és una còpia reordenada de $J$, a parer meu cal considerar la possibilitat que $J$ sigui la còpia en net d'un manuscrit que ja contenia les obres de March en la mateixa disposició diguem-ne caòtica que presenten en J. M'ho fa pensar, per exemple, l'error de còpia dels poemes 30 (v. 1-16) + 26 (v. 25-60), presentats cap al final de la secció II com una sola obra per omissió dels v. 1760 de 30 i 1-24 de 26. Aquestes 8 cobles i tornada, més la rúbrica del poema

3 En $K$ s'ha atorgat el núm. 1 al poema de Chartier, atribuït a March, i el núm. 70 a la Complanta de Pere de Torroella (sense nom d'autor en tots dos testimonis) que encapçala la miscel-lània I. Aquest error no és imputable al reordenador de $K$ —que ha reprès correctament el poema de Torroella després d'inserir la secció marquiana II a continuació de la I-, sinó del numerador de $K$. Cal observar també que, tot i que aquesta numeració exclou les obres atribuïdes a altres poetes (Jaume March, Pere d'Abella), $K$ ha numerat per error l'esparsa «Cell qui mal diu» de Lleonard de Sos amb el núm. 61. Finalment, el numerador de $K$ no atorga cap número a la segona ocurrència del poema $3 \mathrm{i}$ anota al marge que ja consta abans com a núm. 19. Molt significativament, la numeració de $J$ no assigna l'1 a Chartier ni el 70 a Torroella, salta del 60 al 62 i no numera la segona ocurrència del poema 3 -ni les dues esparses del bloc III, no copiades en $K$. És interessant d'observar que la Taula del cançoner $J$ omet la segona ocurrència del poema 3 (sense número, com si fos continuació del poema anterior, tot i que té tornada), les dues ocurrències de l'esparsa $83 \mathrm{i}$, per descomptat, el poema 26, del qual s'han copiat els v. 25-60 com a continuació de les dues primeres cobles del poema 30.

Convé de remarcar que, en el testimoni $K$, una mà més moderna ha anotat al marge de 30: «Aquest cant no és en lo libre» i al v. 8 ha anotat la variant «ans eleges» al costat de la lliçó «ans elegesch» de $J$ i $K$ (March: $A I$ ). Molt probablement, hom no trobava aquest cant al «llibre» de March perquè els testimonis marquians NBKDbcde presenten l'esparsa 29 com a primera cobla d'aquesta cançó, sense separació ni rúbrica; per consegüent, l'íncipit de 30 manca també en les taules alfabètiques corresponents, quan n'hi ha, i també en la de G.

REVISTA VALENCIANA DE FILOLOGIA / I (20I7) p. 6I-94

FRANCESC J. GÓMEZ

Una antologia marquiana a la Barcelona del tercer quart del segle XV / 69 
26, haurien cabut perfectament en un foli de format in folio que el copista de $J$ hauria pogut saltar, en el cas que el seu antígraf ja presentés el poema 30 seguit del 26. Sobre aquest antígraf hom hauria pogut consignar moltes de les lliçons innovadores o contaminacions que de vegades separen $J$ de $L N$, unes intervencions que haurien quedat dissimulades en la còpia en net.

És possible, doncs, que el responsable de l'ordenació caòtica de les obres de March en el cançoner $J$ no sigui pas el seu copista sinó el seu antígraf. No obstant això, cal tornar a insistir que ni $J$ ni el seu antígraf no són pas responsables de la tria de poemes de March incorporats al cançoner. Ben al contrari, $J$ transmet una antologia marquiana preexistent que el seu antígraf hipotètic probablement no solament incorporà i reordenà, sinó també amplià i contaminà amb altres fonts. Es tracta de la mateixa antologia (diguem-ne a partir d'ara $\lambda)$ que hem conservat, tot i que truncada, en $L$.

\section{Reflexos de l'antologia $\lambda$ en els cançoners}

Compareu (en negreta) l'ordre dels poemes marquians compartits pel cançoner fragmentari $L$ i pel cançoner $J$, testimoni $A$ de la tradició textual d'Ausiàs March:

$$
\begin{aligned}
& L: \ldots 6 \ldots 7 \ldots 1,2 \ldots 3,5,9,11,14,16,17,19,21,27,28,29,33 \text {, } \\
& 34,36,37,44,45 \text { (truncat)... } \\
& A(J) \text { : secció I: } 75,|17,16,14,11,9,| 100 \ldots 99-94,92 \ldots \mid \text { 45, 55, 54, } \\
& \text { | } 3 \ldots \text { 1, 2, 3, 4, 5, 6, 7, | } 93 \text { [.. } 83 \text {.. } 82 \text {...] secció II: 87, | 51, 83, 46, } \\
& 44,37,36,34,33,28,27,21,19,29,|80,76,78,81,88,89,90,| 23 \\
& \ldots 38,|49 \ldots 50,53,56,58,69,71,64,77,| 13 \ldots 39,18,42,32 \ldots \\
& 30,26,24,10,31 \text {. }
\end{aligned}
$$

El resultat és ben eloqüent. El copista de $L$ tingué accés a una antologia marquiana $(\lambda)$ que oferia saltuàriament un nombre indeterminat de poesies

REVISTA VALENCIANA DE FILOLOGIA / I (20I7) p. 6I-94 FRANCESC J. GÓMEZ

Una antologia marquiana a la Barcelona del tercer quart del segle XV/ 70 
segons l'ordre canònic, i la incorporà al cançoner aprofitant l'espai en blanc disponible al final del darrer quadern i afegint-ne almenys un de nou, amb la continuació del poema 45, que s'ha perdut. Aquesta antologia $\lambda$ potser començava amb el poema 1 i s'estenia fins al poema 98 o 100 —com en els testimonis monogràfics més antics del corpus marquià. No es pot descartar del tot la possibilitat que el compilador de $L$ o del seu antígraf hagués anticipat els poemes 6 , 7 i 1-2 per copiar-los en espais en blanc dels quaderns precedents, però també és possible que el cançoner $L$ ja tingués integrades aquestes cançons dins la seva miscel-lània de poetes a partir d'altres fonts (recordeu que 6 i 7 també consten en el cançoner de l'Ateneu) i que al copista no li hagués calgut tornar-los a copiar. Del poema 4 no sabem què se n'ha fet: potser no formava part de $\lambda$ o potser fou copiat en algun dels nombrosos folis perduts en aquest cançoner.

Per comparació amb $L$, resulta evident que $A(J)$ ofereix una tria i una ordenació idèntiques en els segments assenyalats: en la secció I recull la sèrie 1-7 conforme a l'ordre canònic, però observeu que $A(J)$ també conté, invertides, les sèries 17, 16, 14, 11, 9, en la secció I, i 44, 37, 36, 34, 33, 28, 27, 21, 19, 29, en la secció II. Pel que fa als poemes 1-7, caldria verificar o rebutjar ecdòticament la possibilitat que l'antecedent comú $\lambda$ contingués aquesta sèrie segons l'ordre canònic conservat en $A(J)$ i, aparentment, desfigurat en $L$. Pel que fa a les altres dues sèries saltuàries, és evident que $A(J)$ testimonia exactament la mateixa tria de poemes que $L$ i en el mateix ordre, encara que invertit. Només cal observar-hi dues excepcions, relatives als dos poemes que no són cançons. D'una banda, l'esparsa 29 no ocupa el lloc que li correspon entre 33 i 28 , perquè, seguida de l'esparsa 80 , totes dues completen el foli $189 \mathrm{v}$, després del final de la cançó 19. D’altra banda, el poema teòric «Los ignorants Amor e sos exemples» (45) s'ha copiat a part d'aquestes dues sèries, potser amb la intenció d'acostar-lo al més extens i teòric dels Cants de mort (92). Finalment, cal remarcar que la cançó 3 s'ha copiat dues vegades en el cançoner $A(J)$ : primer, fora de la sèrie canònica, al f. $47 \mathrm{v}$, just abans de la inserció d'un fragment de balada de Vila-rasa atribuit a Ausiàs March; després, dins la sèrie canònica 1-7. Fóra la prova que en el cançoner $A(J)$ hi conflueixen materials marquians procedents d'altres fonts.

REVISTA VALENCIANA DE FILOLOGIA / I (20I7) p. 6I-94

FRANCESC J. GÓMEZ

Una antologia marquiana a la Barcelona del tercer quart del segle XV / $7 \mathrm{I}$ 
De la resta de poemes d'Ausiàs March transmesos pel cançoner $A(J)$, podem suposar que una bona part també davallen de l'antologia $\lambda$ i que podrien haver figurat en la continuació, malauradament perduda, del cançoner $L$. Remarqueu, per començar, que tots els poemes de la secció I de $A(J)$ que no hem conservat en $L$ són de numeració superior al poema 45 i que, per tant, podrien haver format part de la continuació de l'antologia saltuària que trobem truncada en $L$. Es tracta del llarg poema mitològic "Qui és aquell qui en amor contemple» (75), que inaugura la secció; dels poemes 55 i 54, potser arrossegats en aquesta posició juntament amb el poema 45 , i sobretot dels poemes 92-100, en ordre invertit, com de costum, i amb el poema 93 desplaçat al final de la secció (f. $54 \mathrm{v}-55 \mathrm{v}$ ), no endevino per quina raó.

La secció II és més complexa. S'inaugura amb l'extens poema teòric «Tot entenent amador mi entenga» (87), d'acord amb la tendència del compilador a concedir un lloc rellevant aquesta mena de textos. Però tot seguit se succeeixen diverses sèries saltuàries que corresponen, amb irregularitats menors, a l'ordre canònic, de vegades invertit. L'anticipació dels poemes 87, 75 i 45, així com la col-locació lliure de les cinc esparses marquianes $(29,80,81,82,83)$, hauria pogut desfigurar lleugerament les dues primeres sèries, del poema 19 al 51 (invertida) i del 76 al 90. Una tercera sèrie, del 49 al 77, segueix igualment l'ordre canònic, malgrat la possible anticipació dels poemes 51, 54 i 55, i la posposició del breu poema «Lo temps és tal que tot animal brut» (64) a l'extens "Què m'ha calgut contemplar en amor» (71) per acostar-lo a un altre poema breu com és «No pot mostrar lo món menys pietat» (77).

El fet més sorprenent és que aquesta tercera sèrie s'emmarca entre dotze poemes (en cursiva a l'esquema) que, molt significativament, són les úniques obres anteriors al poema 45 que no figuren en $L$ i, a més a més, només responen parcialment a l'ordenació canònica $(23,38 \ldots 13 \ldots 39,18,42,32 \ldots 30$, $26,24,10,31)$. Mentre que les sèries anteriors —saltuàries però bàsicament conformes a l'ordre canònic - semblen un possible reflex de la continuació de $\lambda$ perduda en el cançoner $L$, hom té la temptació de pensar que aquesta darrera sèrie podria constituir una acumulació de materials marquians complementaris, potser aliens a l'antecedent $\lambda$.

REVISTA VALENCIANA DE FILOLOGIA / I (20I7) p. 6I-94

FRANCESC J. GÓMEZ

Una antologia marquiana a la Barcelona del tercer quart del segle XV / 72 
A diferència del cançoner de l'Ateneu, que aplega les esparses marquianes (80, f. 146v; 29 i 81, f. 147r) dins una secció d'esparses de diversos autors, el cançoner $A(J)$ no aplega pas les esparses 80-83 en una secció d'esparses com la dels folis 103-109 ni com l'ordenació canònica del corpus marquià —el compilador de l'arquetip només deixà de banda l'esparsa 29, potser considerant-la erròniament la primera cobla de la cançó 30 , com fan els testimonis NBKDbcde (vegeu n. 3)—, sinó que, com era habitual, ocupen l'espai deixat en blanc per una altra obra al recto o, més sovint, al verso d'un foli. ${ }^{4}$ Dins la secció II hom ha copiat l'esparsa 83 completant el foli 183v després del poema 51; la 29 i la 80 , completant el foli $189 \mathrm{v}$ després del poema 19 , i la 81 , completant el foli 191r després del poema 78. I, com hem dit més amunt, hom ha copiat les esparses 83 i 82 dins la miscel-lània de poetes dels segles XIV i Xv: la 83 completant el foli 150v després de «Dos grans contrasts són bolcats en ma pensa», de Ramon Boter, i la 82, "Quan plau a Déu que la fusta peresca», completant el foli 157v després de l'obra Contra Fortuna adversa d'Antoni Vallmanya, "Qual un de tants porà dir que ell no senta", de temàtica afí.

Aquestes dues esparses ha estat afegides a posteriori, i manquen no solament en $L$ sinó també en el cançoner de l'Ateneu; per tant, no sembla que figuressin originàriament en aquella miscel-lània de poetes. El seu origen és incert, i també la raó per la qual no es van integrar en l'una o en l'altra de les seccions marquianes. La repetició de l'esparsa 83 — primer afegida dins la miscel-lània de poetes, com la 82 ; després integrada dins la secció II- pot indicar que el copista de $A(J)$ rebé aquestes dues obres d'una altra font quan ja tenia el cançoner avançat. Val a dir que la taula del cançoner no conté l'íncipit de cap d'aquestes dues ocurrències de l'esparsa 83; en canvi, sí que recull l'íncipit de l'esparsa 82, copiada entre altres obres (de Vallmanya i de Ferran d'Ayerbe) de la mateixa temàtica.

Les esparses incloses dins la secció II (83, 29, 80 i 81) no semblen afegides a posteriori, tot i fer sempre la funció de completar el recto o el verso d'un foli. Si

4 Per contra, el seu apògraf $I(K)$ reprodueix l'ordre de $A$ però no pas la seva impaginació, de manera que les esparses no sempre ocupen el final del foli.

REVISTA VALENCIANA DE FILOLOGIA / I (20I7) p. 6I-94

FRANCESC J. GÓMEZ

Una antologia marquiana a la Barcelona del tercer quart del segle XV/ 73 
el copista no reproduïa la impaginació de l'antígraf, probablement recorria a la seva reserva d'esparses - de March o d'altri- quan ho considerava convenient. La 29 davallava amb tota probabilitat de $\lambda$, i és possible que les altres també. La 29 i la 80 presenten variants comunes amb el cançoner de l'Ateneu.

\section{El testimoniatge de les variants textuals}

L'antologia hipotètica $\lambda$ no solament es perfila en la tria i l'ordenació de les poesies, sinó també en una llista considerable de variants comunes i d'errors conjuntius que confirmen no solament el parentiu entre els testimonis que en davallen (AILM), sinó també entre $\lambda$ i alguns altres testimonis del corpus marquià que pertanyen a la mateixa branca de la tradició. Aquesta observació és important, perquè, per als textos de $A I$ no conservats en $L M$, l'única manera d'argumentar la seva probable pertinença a l'antologia $\lambda$ serà: $a$ ) l'aparició en una sèrie saltuària conforme a l'ordre canònic; $b$ ) la confirmació d'un parentiu textual significatiu amb els altres testimonis de la mateixa branca. En el present estudi em limitaré a discutir les variants més significatives dels vint-i-dos poemes compartits actualment per $A L$ o $A L M$, amb l'esperança de fer-ne un balanç més precís que el que ofereixen Pagès (1912-1914: I, 124-144, esp. 128-130) i Archer (1997: II, 24-28).5

5 Tot i que he tingut molt en compte l'aparat, complet i rigorós, de Robert Archer, he col·lacionat personalment els testimonis de tots aquests textos, excloent-ne expressament les cinc edicions del segle XVI (abcde), el manuscrit $C$, descriptus de l'edició $c$, i el manuscrit $E$, basat en diversos testimonis manuscrits i edicions. En canvi, sí que he inclòs en la col·lació els manuscrits cinc-centistes $B K D G_{2}$, capaços de projectar alguna llum sobre la filiació dels testimonis més antics, $H A L M N F G_{1}$; del testimoni $I$, apògraf de $A$, només en comento les lliçons quan ho considero convenient per a l'anàlisi. Així doncs, a més de AILM, els testimonis marquians col-lacionats són: $H$, Saragossa, Biblioteca Universitaria, ms. 210; N, Nova York, Hispanic Society of America, ms. B. 2281; F, Salamanca, Biblioteca Universitaria, ms. 2244; G, València, Biblioteca Universitària, ms. 210; B, París, Bibliothèque Nationale, ms. esp. 479; K, Barcelona, Biblioteca de Catalunya, ms. 2025; D, Madrid, Biblioteca Nacional, ms. 2985. L'escrutini de les variants és volgudament selectiu: prescindeixo de variants gràfiques, morfològiques, sinonímiques o clarament poligenètiques, sense cap mena de valor de filiació; també prescindeixo, en general, d'innovacions i variants singulars, tan abundants i profundes en alguns testimonis, com ara $B$. Per claredat, i també per evitar tant la dispersió de variants gràfiques com la temptació d'atribuir-hi un fals valor de filiació, aplico a les lliçons un mínim criteri de regularització gràfica, tret que l'anàlisi recomani de mantenir la grafia antiga.

REVISTA VALENCIANA DE FILOLOGIA / I (20I7) p. 6I-94

FRANCESC J. GÓMEZ

Una antologia marquiana a la Barcelona del tercer quart del segle XV/ 74 
A propòsit del testimonis més antics, convé de recordar que Jaume Torró (2010: 380-381) ha argumentat de manera convincent que el cançoner de Saragossa $(H)$ fou copiat per algú relacionat amb Lleida i amb la cort del príncep Carles el 1461 o, en tot cas, abans del juliol de 1462, i que originàriament no era pas una antologia ni una miscelllània, sinó que s'obria amb un cançoner monogràfic marquià, posteriorment ampliat, gairebé tan complet com els testimonis $F$ i $N$. Més recentment s'ha argumentat també que el cançoner de Nova York $(N)$ podria haver estat encarregat, i parcialment copiat, pel poeta tarragoní Lluís d'Avinyó ( «mossèn Avinyó»), mort abans del 8 de juliol de 1477 (Ramos, Rodríguez Risquete \& Torró 2014). És probable, doncs, que els cançoners HAILMN fossin copiats a Catalunya en un període molt curt (1461/1477), alhora que probablement hom copiava a València els cançoners $F$ i $G_{1}$, com suggereix Beltran (2006b: 159-165).

\subsection{La sèrie saltuària de $A L$}

La seqüència dels testimonis $A L$ demostra que els poemes $9,11,14,16$, $17,19,21,27,28,29,33,34,36,37$ i 44 remunten sens dubte a un antecedent comú, i l'ecdòtica ho confirma. Algunes composicions $(14,34)$ no aporten cap variant significativa, però les altres ofereixen, en conjunt, un nombre suficient de llocs crítics.

Poema 9 (manquen H[1-24]MG ${ }_{1}$ ). Variants d'escàs valor ecdòtic.

6 d'entrar dins tal presó $A L F B D G_{2}$ ] en $N K$

25 Estant a part $e$ sol $A L N F B K]$ tot $H D G_{2}$

Poema 11 (manquen $M G_{1}$ ). AL comparteixen dos errors en els versos de

l'íncipit (v. 1-2) i en un canvi d'ordre (v. 39) que no afecta el sentit ni la

mètrica.

1 Quins tan segurs $\left.H F B K D G_{2}\right]$ tants $A L:$ tals $N$

2 Cor malastruc $H F B D G_{2}$ ] Cors $A L N$ : Cos $K$

39 contra mi és ardida $H F D G_{2}$ ] és contra mi $A L N B K$

Poema 16 (manquen $M G_{1}$ ). Una variant (v. 40) confirma la relació $H G_{2}$. 40 la mia desventura $A L N F B K D$ : ma gran desaventura $H_{2}$

Poema 17 (manquen $M G_{1}$ ). Nombrosos llocs crítics confirmen que $H$

REVISTA VALENCIANA DE FILOLOGIA / I (20I7) p. 6I-94

FRANCESC J. GÓMEZ

Una antologia marquiana a la Barcelona del tercer quart del segle XV/ 75 
(generalment amb $D G_{2}$ ) presenta lliçons diferenciades de la resta de testimonis. La lliçó de $A L N B K$ en el v. 26 es pot considerar un error banalitzador. En el v. 16 alguns testimonis presenten una lliçó ambigua (causa o cansa).

13 D'amor ho dich $A L N F B K$ : Cest (Est $D$ ) és amor $H D G_{2}$ 16 se causa d'esperar (desesperar $K) A L N F B K$ : port·a nós l'esperar $H D G_{2}$

26 car en pochs cau $H_{F D G_{2}}$ ] és $A L N B K$

30 volent-li donar volta $A L N F K G_{2}$ : esperant rebre volta $H D: B$

innova

40 foll gosar $A L N F B K$ : ardiment $H D G_{2}$

Poema 19 (manquen $H M G_{1}$ ). Es confirma (en absència de $H$ ) la relació $D G_{2}$.

10 de què se desespera $A L N F B K]$ no haja (haig $D$ ) esper $D G_{2}$

11 cosa vera $A L N F B K$ : sia ver $D G_{2}$

26 jo·m só représ $A L N F K$ : bé m’ha représ $D G_{2}: B$ innova

30 no·n (no $A L$ ) sé pus empobrit $N F B K]$ no·n só $D G_{2}$

Poema 21 (manquen $M G_{1}$ ). Una variant confirma la relació $H D G_{2}$.

31 per negun temps peresca $A L N F K$ : per null temps no peresca

$\mathrm{HDG}_{2}:$ B innova

Poema 27 (manquen $M G_{1}$ ). AL i $B$ coincideixen en un error poligenètic $(l o m>l \bar{o}>l o)$.

9 l'hom flac $H N F K D G_{2}$ : lo $A L B$

Poema 28 (manquen $H M G_{1}$ ). AL coincideixen constantment amb NBK, tot i que es tracta de variants adiàfores o poligenètiques. En absència de $H, D G_{2}$ s'oposen a la resta de testimonis en els v. 11 i 16 .

2 ses tenebres $F D$ ] les $A L N B K G_{2}$

9 faç pus que si matàs $F D$ ] pits $A L N K G_{2}$ : pejor $B$

11 jo solt per trair me $A L N F B K]$ he trets $D G_{2}$

16 per donar-me ofensa $A L N F B K]$ complir ma $D G_{2}$

Poema $29\left(\right.$ manca $\left.G_{1}\right)$. En NBKD no hi ha separació entre aquesta esparsa i el poema 30. En $G_{2}$ els separa la rúbrica, i $H A L M F$ indiquen expressament que el 29 es tracta d'una esparsa; de fet, en $M$ (f. 147r) es copia entre les esparses $80(146 \mathrm{v})$ i $81(147 \mathrm{r})$, i en $A$ s'ha desplaçat després del poema 19 per a completar el foli $189 \mathrm{v}$ juntament amb l'esparsa 80.

REVISTA VALENCIANA DE FILOLOGIA / I (20I7) p. 6I-94

FRANCESC J. GÓMEZ

Una antologia marquiana a la Barcelona del tercer quart del segle XV / 76 
En el v. 6, els testimonis $A L M N B K$ comparteixen un error comú conjuntiu (potser a partir de la confusió esforc > esgort $>$ esguard). La mateixa oposició amb $\mathrm{F}$ i $\mathrm{HDG}_{2}$ es confirma en la forta innovació del v. 8 . $H$ (acompanyat de $D$ ) presenta una altra variant adiàfora en el v. 3 .

1 se' $n$ va $\left.H F B K D G_{2}\right]$ se $A L M N$; pel desert $\left.H M F\right]$ per $A L N B K D G_{2}$ 3 ne torna mai $A L M N F B K G_{2}$ : ne vol tornar $H D$

6 mon esforç ha confús $H F D G_{2}$ ] esguard $A L M N B K$

8 la gran paor qui $\cdot \mathrm{m}$ tol ser delitós $H F D G_{2}:$ los pensaments qui $\cdot \mathrm{m}$ porten les paors $A L M N B K$

Poema 33 (manquen $H M G_{1}$ ). El grup $A L$ es fa visible en la variant del v. 16; l'oposició $F D G_{2}: A L N B K$ en la menys significativa del v. 4. D'altra banda, l'oposició entre $D G_{2}$ (en absència de $H$ ) i la resta de testimonis és evident en els v. 20, 23, 24 i sobretot 38-40. En els v. 3839 constatem dues interpretacions discrepants d'una lliçó difícil i un intent poc reeixit de correcció innovadora en $D$.

4 e par-ho bé que no us vull $F D G_{2}$ ] car $A L N B K$

16 que perd lo sentiment $\left.N F B K D G_{2}\right]$ qui $\cdot \mathrm{m}$ tol $A L$

20 no és en cors $A L N F B K]$ tot $D G_{2}$

23 que pot ésser perida $A L N F B K]$ partida $D G_{2}$ 24 no s'hi troba·sforçada (forçada NB) $A L N F B K$ : no hi és molt esforçada $D G_{2}$

38 per ço amor de mi no•s partirà (partrà $D^{a c}$ ) $A L N F B K D^{a c}$ : per ço que amor de mi jamés no·s parta $D^{p c}$ : per ço amor en mi no s'apartà $G_{2}$ 39 Aquell-amor (La part d'amor $B$ ) qu·en nostra carn està $A L N F B K$ : car l'amador qui son voler fartà $\left.D^{a c}\right]$ no farta $D^{p c}$ : fart ha $G_{2}$ 40 no met (cria $B$ ) al cor lo no cansable verme $A L N F B K$ : no·l rou d'amor $D G_{2}$

Poema 36 (manquen $H M G_{2}$ ). Constatem el grup $A L$ (v. 13 i 38) i l'oposició $F D\left(\operatorname{ara} a m b G_{1}\right): A L N B K$ (v. 27 i 28). L'error del v. 6 no és conjuntiu ni separatiu.

6 anant a quell $A L F G_{1}$ : amant aquell $N B K D$

13 torbant $N F G_{1} B K D$ : torbat $A L$

27 A vostr.amor lo meu cor s'abandona $F G_{1} D$ ] Lo meu voler al vostre $A L N B K$

REVISTA VALENCIANA DE FILOLOGIA / I (20I7) p. 6I-94

FRANCESC J. GÓMEZ

Una antologia marquiana a la Barcelona del tercer quart del segle XV / 77 
28 Lo vostre cors per deessa vull colre $F G_{1} D$ ] En aquest món [...] us vull $A L N B K$

38 mon mal $N F G_{1} B K D$ : mos mals $A L$

Poema 37 (manquen $M G_{2}$ ). El grup $A L$ presenta dos errors comuns poc significatius (v. 1 i 22), així com HD comparteixen una variant que la primera mà de $H$ ha corregit (v. 5). En el v. 22 el testimoni $B$ se separa excepcionalment — per contaminació? - de la lliçó errònia de $A L N K$ (repetició de «mon voler» del v. 21) i acull la lliçó correcta de $H F G_{1} D$.

1 d'alguna causa mou $\left.H N F G_{1} B K D\right]$ cose.s $A$ : cosa $L$

5 que.m veda tot repòs $\left.H^{p c} A L N F G_{1} B K\right]$ mon $H^{a c} D$

22 mon esforç sent decréixer $\left.H F G_{1} B D\right]$ voler $A L N K$

33 Los mals tan grans $H N F G_{1} B K D$ ] greus $A L$

Poema 44 (manquen $M G_{2}$ ). Les variants del v. 11 oposen $A L N B K$ i $H F G_{1} D$ : la lliçó del segon grup sembla un error comú per anticipació de «mon mal» del v. 12, però és possible que la lliçó del primer grup sigui innovació del subarquetip comú, per a evitar justament aquesta repetició. El cançoner $H$ ofereix algunes lliçons singulars (v. 4, 20); en absència de $G_{2}, H D$ presenten algunes coincidències, especialment la del v. 19, amb permutació de mots i omissió del determinant $u$ n.

11 mon mal a fi venrà $H F G_{1} D$ ] fet $A L N B K$

19 tots los meus jorns un moment semblaran $\left.A L N F G_{1} B K\right]$ jorns meus moments (moment $D$ ) me $H D$

La varia lectio d'aquesta sèrie confirma parcialment la divisió de la tradició en dos grups principals $\left(H F G_{1}\right.$ i $\left.A L M N\right)$ establerta per Amadeu Pagès (1912-1914: I, 128-130 i 147). Dic parcialment, perquè pràcticament no es troben errors comuns conjuntius que certifiquin la relació genètica del primer grup. Per contra, una llista considerable d'errors comuns $(11,1-2,39$; 17, 26; $33,4 ; 37,22)$, entre els quals n'hi ha que podríem considerar conjuntius i separatius $(29,6,8 ; 36,27-28)$, permet d'afirmar que, com a testimonis d'aquesta quinzena de poemes, $A L M N$ (generalment, també $B K$ ) remunten al subarquetip que Pagès designà amb la sigla ${ }_{1} \mathrm{X}^{2}$ (diguem-ne $\beta$ ).

Dins aquest grup $\beta$, els testimonis $A L$ són descendents d'un subarquetip comú, responsable d'un petit nombre de lliçons i d'errors comuns significatius

REVISTA VALENCIANA DE FILOLOGIA / I (20I7) p. 6I-94 FRANCESC J. GÓMEZ

Una antologia marquiana a la Barcelona del tercer quart del segle XV / 78 
$(27,9 ; 28,2,9 ; 33,16 ; 37,1,33)$. A parer meu, aquest subarquetip comú hauria d'ésser $\lambda$, responsable de la selecció i de l'ordre dels poemes transmesos per $A L$. Les nombroses lliçons singulars de $A$ i $L$ fan pensar que no són pas còpia l'un de l'altre. En l'esparsa 29, $M$ llegeix amb $A L$.

Els testimonis $H F G_{1}$ (en general, també $D G_{2}$ ) podrien davallar, així mateix, del subarquetip que Pagès designà amb la sigla ${ }_{1} \mathrm{X}^{1}$ (diguem-ne $\alpha$ ), però l'absència freqüent de $H$ i $G_{1}$ dificulta la discussió dels errors comuns (vegeu el comentari de 44). És interessant d'observar que $H$-probablement el testimoni més antic - presenta nombroses lliçons peculiars en oposició a $F$ i a $\beta(16,40$; $17,13,16,30,40 ; 21,31 ; 29,3 ; 37,5 ; 44,19)$. Els testimonis tardans $D G_{2}$ recullen sovint, encara que no sempre, aquestes lliçons peculiars de $H$.

\subsection{La sèrie 1-7}

Els poemes 1-7 s'han transmès en $A$ com una sèrie contínua (no saltuària) conforme a l'ordre canònic en successió recta (no pas inversa), i presenten la particularitat, potser rellevant, d'obrir quadern (f. 49r). Són trets que la diferencien de la sèrie que acabem d'estudiar.

En el cançoner $L$ manca el poema 4, mentre que els poemes 6, 7 i 1-2 apareixen copiats per separat dins una extensa miscel-lània de poetes dels segles XIV i $\mathrm{xv}$; els poemes 3 i 5 encapçalen la secció marquiana final, reprenent l'ordre canònic, i sembla gairebé segur que formaven part de l'antologia $\lambda$. Els quatre poemes anticipats no semblen copiats a posteriori, i els poemes 2 i 7 contenen esmenes de la mateixa mà, però d'un moment posterior, que acosten encara més la lliçó de $L$ a la de $A$. Els poemes 6 i 7 són els únics d'aquesta sèrie també inclosos en el cançoner de l'Ateneu $(M)$, amb lliçons que evidencien un parentiu particular amb $L$.

Cal remarcar que la cançó 3 s'ha copiat dues vegades en el cançoner $A$ : primer $\left(A^{1}\right)$, fora de la sèrie canònica, al f. $47 \mathrm{v}$, just abans de la inserció d'un fragment de balada de Vila-rasa atribuït a Ausiàs March; després $\left(A^{2}\right)$, dins la sèrie 1-7. La primera cobla de la cançó 3 també és citada dins el poema «Tant mon voler» de Pere Torroella, transmès pels cançoners de Saragossa i Nova York; per tant, d'aquesta cobla en tenim dos testimonis indirectes $\left(H N^{2}\right)$, a més dels testimonis del corpus marquià.

REVISTA VALENCIANA DE FILOLOGIA / I (20I7) p. 6I-94

FRANCESC J. GÓMEZ

Una antologia marquiana a la Barcelona del tercer quart del segle XV / 79 
Pel que fa al conjunt de la tradició, cal recordar que $H$ contenia aquesta sèrie, però que actualment hi manquen les cançons 1-6 i la primera cobla de la 7 per la pèrdua del primer quadern (Torró 2010: 387). La cançó 1 manca en $F$ per la pèrdua d'un foli inicial, i per això hi fou tornada a copiar al segle xvi segons l'edició de Romaní de 1539 (Pagès 1912: 32). La part més antiga del cançoner de València $\left(G_{1}\right)$ transmet els poemes 4-6; la més tardana $\left(G_{2}\right)$ els conté tots menys el 4 i el 5 , i copia dues vegades el $2\left(G_{2}{ }^{1}\right.$ i $\left.G_{2}{ }^{2}\right)$. Totes aquestes absències dificulten la discussió ecdòtica, especialment pel que fa a la posició de $H$ i de $G_{1}$.

Com molts dels poemes de la sèrie saltuària 9-44, el poema 4 (sense $H G_{2}$ ni $L M)$ no aporta errors comuns de filiació, mentre que els poemes 3 i 5 no presenten errors exclusius de $A L$, però almenys en el poema 5 se'n confirma la pertinença a la família $\beta$. A més a més, les dues versions del poema 3 , comparables amb el testimoniatge indirecte de Pere Torroella, revelen que $\lambda$ transmetia en l'íncipit l'error d'arquetip que presenten tots els testimonis marquians tret de la primera versió de $A\left(A^{1}\right)$, el cançoners tardans $D G_{2}$ i una mà correctora de $F$; certament, manca $H$, que sovint presenta variants recollides per $D G_{2}$, i, per tant, cal considerar la possibilitat —inverificable—d'una relació entre $A^{1}$ i $H D G_{2}$ :

Poema 3 (manquen $H \mathrm{HG}_{1}$ ). En $A$ és copiat dues vegades: fora de la sèrie canònica $\left(A^{1}\right)$ i també dins $\left(A^{2}\right)$, mentre que la primera cobla és també citada dins «Tant mon voler» de Pere Torroella $\left(H N^{2}\right)$. En l'íncipit la lliçó correcta «Alt e amor» és transmesa per Torroella $\left(H N^{2}\right)$, per $A^{1}$ i pels tardans $D G_{2}$, mentre que tots els altres testimonis copien el poema 3 dins la sèrie canònica amb l'error «Per molta amor» (en $F$ una mà posterior ha ratllat l'error i l'ha corregit), imputable a l'arquetip de l'ordenació canònica. La lliçó de $A^{1}$ testimonia que el compilador de $A$ va accedir a un testimoni lliure d'aquest error, potser una font extravagant.

1 Alt e amor $A^{1} F^{p c} D G_{2}$ Torroella: Per molta amor $A^{2} L N F^{a c} B K$ 4 magrir carn $A^{1} A^{2} L F B K D G_{2}$ : morir tan $N$ : languir carn Torroella Poema 5 (manquen $\mathrm{HMG}_{2}$ ). No hi ha errors que agrupin particularment $A L$, però algunes variants adiàfores insinuen una oposició entre $A L N B K$ i $F G_{1} D$, malgrat el comportament fluctuant o innovador de $B$ :

REVISTA VALENCIANA DE FILOLOGIA / I (20I7) p. 6I-94 FRANCESC J. GÓMEZ

Una antologia marquiana a la Barcelona del tercer quart del segle XV / 80 
12 mai lo Satan lo pog ben discernir $\left.F G_{1} D\right]$ aquell pog $A L N K$ : lo pogue $B$ 30 só restat malmirent $F$ ] só estat $A L N B K$ : seré estat $G_{1} D$

Els poemes 6 i 7 , anticipats en $L$, també són presents en $M$ i, sortosament, conservem el testimoniatge de $H$ en el cas del poema 7 (sense la cobla inicial). És evident que $L M$ davallen d'un antecedent comú, potser el mateix antígraf de $L$ que, en algun cas, $M$ hauria pogut esmenar per conjectura (7, 25 i 43). Però la pertinença a la família $\beta$ no és gens clara. En el v. 4 del poema 6 , $L M$ comparteixen dues variants amb $N D G_{2}$, però $A$ només una. En el poema $7 A L M$ presenten nombrosos errors comuns i tres variants amb $H$ (v. 16, 21, 65), però cap amb $N$, i, per tant, no se'n confirma la pertinença a $\beta$. Podem sospitar, doncs, amb la cautela deguda, que en aquest cas la font de l'antecedent comú de $A L M$ no fou pas $\lambda$, sinó alguna altra font afí al testimoni $H$, i també que l'antologia $\lambda$ no contenia el poema 7 ; altrament, els compiladors haurien pogut omplir una llacuna del v. 47 (e [ ] adeu $A^{a c} I^{a c} L M$; les esmenes de $A$ i I són degudes a una intervenció posterior). Una correcció de $L(7,40)$, potser de la mateixa mà però practicada a posteriori, coincideix amb una lliçó innovadora de $A$; sembla, doncs, que la revisió d'aquest vers es dugué a terme a la vista de $A$ o del seu antígraf $A$ '.

Poema 6 (manca $H)$. No hi ha errors que agrupin particularment $A L$; en canvi, abunden el llocs — no els recullo tots- que evidencien una relació molt estreta entre $L M$ (v. 3, 4, 7-9, 17, 24, 29, 31, 35, 39, 47); tots dos presenten algunes lliçons singulars, sobretot $M$, però no significatives ni clarament separatives. En la difracció del v. 4 cal comptar $L$ al costat de $M N$ en oposició a $F G_{1}$ : però els testimonis tardans $B K$ presenten un comportament poc habitual, llegint amb $F G_{1}$, així com fa $A$ en el segon hemistiqui. No podem saber si les lliçons de $D G_{2}$ recullen el testimoni perdut de $H$.

2 per joventut $\left.A L M N F G_{1} B K\right]$ lo jovent $D G_{2}$

3 és mal coneixent $A N F G_{1} B K D G_{2}$ ] no és $L M$

4 e ja pus fort $F G_{1} B K$ : e majorment $A L M N D G_{2}$; havent raó malalta

REVISTA VALENCIANA DE FILOLOGIA / I (20I7) p. 6I-94

FRANCESC J. GÓMEZ

Una antologia marquiana a la Barcelona del tercer quart del segle XV / 8I 
$A F G_{1} B K$ : si la raó és malalta $M N D G_{2}$ : si ha (esmenant la) raó malalta $L$

8 deu ésser nomenat $\left.A N F G_{1} K D G_{2}\right]$ vol $L M B$

24 quals (qual $K$ ) veritat desfà $A N F G_{1} B K D G_{2}$ : que un infant poc desfà $L M$

39 del (de F) mal del companyó $A N F G_{1} B K D G_{2}$ ] de son bon $L M$ 47 no sofir $A N F G_{1} B K D G_{2}$ : no consent $L M$

51 pus flac e fort $A L M N F B K]$ franc $G_{1} D G_{2}$ Poema 7 (manquen $H[1-8] G_{1}$ ). Es confirma la relació $L M$ (v. 7, 8, 26, $40)$, però en aquest cas hi ha moltes lliçons que agrupen particularment $A L$ o $A L M$ (v. 12, 23, 25, 32, 40, 43, 46, 47, 57, 60). El v. 12 ofereix un bon exemple d'error conjuntiu separatiu. El v. 40 és molt significatiu. Dins l'epitafi poètic que el poeta imagina en la seva tomba (v. 39-40):

Plena de seny, no tingau a gran bomba car per vós muir e vaig no sabent on,

$M$ manté la lliçó presumiblement originària del grup ( «com per vós mort só e vaig no sé on»), coherent amb el context. $L^{a c}$ llegeix exactament igual que $M$, però una mà correctora hi ha practicat dues esmenes ( «... muir e vaig no sé $a$ on») que coincideixen exactament amb la lliçó de $A$ i només parcialment amb la resta de testimonis («...muir e vaig no sabent on»). Aquest indici suggereix una relació entre $A$ (o el seu antígraf $A^{\prime}$ ) i les correccions de $L$, que no són gens freqüents en el conjunt del cançoner. El v. 47 també és revelador: $A^{a c} I^{a c} L M$ presenten un espai en blanc que deriva de llur antecedent comú, i només una segona mà correctora ha estat capaç d'omplir el buit tant en A com en $I$. Per tant, ni el corrector de $L$ ni tampoc els responsables de $A$ no disposaven de cap testimoni complementari.

Cal destacar les lliçons comunes, probablement errors, de $H$ amb ALM contra $N F$ (v. 16, 21, 65). En absència de $H$, hi ha dues coincidències (v. $7,8)$ dels testimonis tardans $D G_{2}$ amb $L M$.

3 mas tant com l'amador $A L M N F B K]$ sinó $D G_{2}$

7 o és adjunt (o ajunt) ab una tal esposa $A N F B K]$ lligat $L M D G_{2}$ 8 son dret nom (nom dret $N K$ nom $B$ ) apellat $A N F B K]$ lo $L M D G_{2}$

REVISTA VALENCIANA DE FILOLOGIA / I (20I7) p. 6I-94 FRANCESC J. GÓMEZ

Una antologia marquiana a la Barcelona del tercer quart del segle XV / 82 
11 no pot ser fin amant $H A N F B K D G_{2}$ ] poch $L M$

12 ne lo subtil $H N F B K D G_{2}$ : ne subtil gens $A L M$

16 axí Amor en cap d'om foll atura NFBK] tan poc amor

$\mathrm{HALMDG}_{2}$

21 Verdader fon (o fo・n) son dit NFK] sos dits $H A L M D G_{2}: B$

innova

23 mas en est cas entre ells ha malvolença $\left.H N F K D G_{2}\right]$ aquest $A L M$

: B innova

25 amor amant se conqueria $H M N F B K D G_{2}$ ] encorria $A L$

26 maestria $H A N F B K D G_{2}$ : manestria $L M$

32 car viure ab mals $H N F B K D G_{2}$ ] ells $A L M$

40 car $H N F B K D G_{2}{ }^{a c}$ : com $A L M G_{2}{ }^{p c}$; muyr e vaig

$H A L^{p c} N F B K D G_{2}{ }^{a c}$ : mort só (sui $G_{2}^{p c}$ ) e vaig $L^{a c} M G_{2}{ }^{p c}$; no sabent on

$H N F B K D G_{2}$ : no sé on $L^{a c} M$ : no sé a on $A L^{p c}$

43 envejats $H I^{p c} M N F B K D G_{2}$ : enujats $A I^{a c} L$

46 sent grans dolors $H N F B K D G_{2}$ ] sens ALM; folls moviments

$\left.H N F B K D G_{2}\right]$ forts $A M$ : fort $L$

47 e vós haveu $H A^{p c} I^{p c} N F B K D G_{2}$ : e [ ] adeu $A^{a c} I^{a c} L M$

57 no crec l'haja perdut $H N F B K D G_{2}$ ] haja $A L M$

60 me trobe mut $H N F B K D G_{2}$ ] m'he trobat $A L M$

65 tot mon seny vull despendre $\left.N F K D G_{2}{ }^{a c}\right]$ temps $H A L M B G_{2}{ }^{p c}$

Gràcies al poema 3 hem constatat que, almenys $A$, va recollir testimonis ocasionals d'altres branques o, fins i tot, extravagants. Això podria explicar les peculiaritats de $A$ en el poema 1 , però cal lamentar l'absència de quatre testimonis antics. D’altra banda, en els poemes 1 i 2 , com en el poema 6, manquen errors exclusius que confirmin clarament la relació entre $A L$, tot i que $L$ sí que presenta alguna variant comuna amb $\mathrm{N}$ i/o $D G_{2}$ (esp. 2, 9). El poema 2 presenta unes quantes esmenes a posteriori.

Poema 1 (manquen $H_{F G} M$ ). A llegeix contra tots els altres testimonis $\left(L N B K D G_{2}\right)$ en els v. 8, 9, 10 i 28, però les seves lliçons singulars han estat considerades preferibles per Bohigas (1952-1959: II, 5-6) i altres

REVISTA VALENCIANA DE FILOLOGIA / I (20I7) p. 6I-94

FRANCESC J. GÓMEZ

Una antologia marquiana a la Barcelona del tercer quart del segle XV / 83 
autors. ${ }^{6} L$ també presenta lliçons singulars en els v. 5-6, 10-12, 15-16, 32 i 35, però tenen tot l'aspecte d'innovacions davant lliçons defectuoses o llacunoses. No hi ha errors comuns que confirmin el grup $A L$. En absència de $H F G_{1}$, les coincidències amb $N B K$ (v. 5, 10, 35) esdevenen menys significatives.

5 Sentint (Veent $B$ ) estar en aguait $A N B K$ : Sabut de cert l'aguait de $L$ : Sentint venir l'aguait de $D G_{2}$ 6 sabent de cert $A N B K D G_{2}$ : e no ignor $L$ 8 aquell passat $A$ : ço que és no res $L N K D G_{2}: B$ innova 9 Del temps present no.m trobe amador $A: \mathrm{Al}(\mathrm{Del} N)$ temps passat me trobe (trob en $N$ ) gran amor $L N B K D G_{2}$ 10 mas del passat, que és no res e finit $A$ : amant (ez am $L$ ) no res, puix és ja tot (tot ja $L D G_{2}$ ) finit $N B K D G_{2}$

11 D'aquest pensar $A N B K D G_{2}$ : Aquest pensar $L$; me sojorn e.m delit $A N K D G_{2}$ : m'és sojorn e delit $L$ : jo sent molt gran delit $B$ 12 s'esforça ma dolor (tristor $B) A N B K D G_{2}$ : doble és (o dobla's) ma gran dolor $L$

15 e creure.l fan $A N B K D G_{2}$ : e li és dit $L: B$ innova

16 sense un punt $A N B K D G_{2}$ ] jorn $L$

19 lo pensament $A$ ] son $L N B K D G_{2}$

20 report $A N K D G_{2}$ : aport $L B$

21 e $A N B K D G_{2}:$ ans $L$

28 passat plaer $A K^{p c}$ : plaser pensat $L$ : pensat plaer $N B K^{a c} D G_{2}$

32 tot son menjar en dolor se nodreix : tot lo dinar al ventrell li podreix $L$

35 essent llong temps $A N B K]$ tant ha $L D G_{2}$; lloc poblat $A N B K D G_{2}$ : los poblats $L$

6 En la primera cobla el poeta confessa que es complau exclusivament en la imaginació del passat per la certesa del desastre esdevenidor. Només la lliçó de $A$ fa referència al present per a rebutjar-lo (v. 9), perquè tampoc no aporta cap delit a la imaginació de l'amant: a part del passat, cap «altre bé no hi habita» (v. 4). Una idea semblant, en un context diferent, s'expressa en 95, 36: «de mos tres temps me resta lo que fon». La lliçó dels altres testimonis repeteix, en canvi, innecessàriament la idea que el passat és no res (v. 8: «ço que és no res», i 10: «amant no res»); insisteix, per tant, en la idea que aquest delit és un «foll pensament» (v. 2). A una fàcil confusió paleogràfica entre present, passat i pensat (v. 28), s'hi podria haver afegit la influència d'una lectura penitencial, influïda pel sonet prologal de Petrarca «Voi ch'ascoltate» (Cabré \& Turró 1995).

REVISTA VALENCIANA DE FILOLOGIA / I (20I7) p. 6I-94

FRANCESC J. GÓMEZ

Una antologia marquiana a la Barcelona del tercer quart del segle XV / 84 
Poema 2 (manquen $H M G_{1}$ ). L presenta moltes lliçons peculiars i manquen errors que confirmin la relació $A L$. A més a més, en el v. 9 sorprèn la coincidència de $L N D G_{2}$ contra $A F B K$, semblant a la que hem vist en el v. 4 del poema 6. D'altra banda, una mà correctora posterior $\left(L^{p c}\right)$ ha fet esmenes (v. 3, 5, 7, 16) i ha afegit el v. 6, que mancava.

La voluntat de reparar aquesta llacuna podria haver motivat alguna conjectura (v. 3) i la comparació amb algun altre testimoni - potser A o el seu antígraf $A^{\prime}$ (v. 7)—, però cal observar que el corrector no esmena totes les lliçons singulars, sinó només les que li semblen defectuoses.

1 Pren-me'n així $A N F B K D G_{2}$ : Atressím pren $L$

3 Veent $A L^{a c} N F B K D G_{2}$ : e veu $L^{p c}$; lo cel $L N F B K D G_{2}$ : lo temps $A$

5 E sent $A L^{p c} N F B K D G_{2}:$ Sentint $L^{a c}$

6 om. $L^{a c}$

7 Lleva son jui $\left.A L N F B K G_{2}{ }^{1}\right] \mathrm{Fa}_{D G_{2}}{ }^{2}$; si molt és $A L^{p c} F K$ : si és molt $N B D G_{2}$ : si és ges $L^{a c}$

9 Moltes veus és que·l vent és fortunal $A F B K$ : Mes a les veus és lo vent fortunal $L N D G_{2}$ 13 trobant-me enamorat $A N F B K D G_{2}$ ] car sui $L$

16 mas un sol pas meu no hi serà trobat $\left.A L^{p c} N F B K D G_{2}\right]$ menys $L^{a c}$

17 és en lo bosc $A N F B K D G_{2}$ : serà en los boscs $L$

$19 \mathrm{La} \mathrm{mia}$ amor $A N F B K D G_{2}$ : Ma gran $L$

25 he dat mal $A N F B K D G_{2}:$ no us he dat $L$

37 magresa $A N F B K D G_{2}:$ margor $L$

39 Lo cos molt gras $A N F B K D G_{2}$ : car lo cos gras $L$

El comportament de la tradició en la sèrie canònica 1-7 resulta força complex. Les úniques certeses són el parentiu de $L M$ en les cançons 6 i 7 i de $A L M$ en el poema 7. En absència de $M$, especialment en els poemes 1 i $2, L$ presenta nombroses lliçons singulars imputables al copista o al seu antecedent.

Només es recull algun indici clar d'afinitat amb $\beta$ en la cançó 5; en les cançons 2 i 6 són més ambigus, perquè la coincidència sol ésser amb $N$ i $D G_{2}$ i perquè $A$ se separa de $L N(6,4 ; 2,9)$; en el poema $7, A L M$ es més afí a $H D G_{2}$ que no pas a $N$. En aquestes condicions, no podem assegurar que l'antologia $\lambda$ contingués la sèrie $1-7$, especialment el poema 7 .

REVISTA VALENCIANA DE FILOLOGIA / I (20I7) p. 6I-94

FRANCESC J. GÓMEZ

Una antologia marquiana a la Barcelona del tercer quart del segle XV/ 85 
Tot fa pensar que el col-lector dels materials del cançoner $A$ també disposà de fonts alternatives en alguns casos, atès que $A$ recull una versió correcta de l'íncipit de la cançó $3\left(A^{1}\right)$ i presenta en el poema 1 lliçons força satisfactòries totalment singulars (manquen, però, $H F G_{1}$ ). Si s'admet que les lliçons de $A$ són genuïnes i no pas innovacions, cal suposar que les variants dels altres testimonis remunten probablement a l'arquetip de la sèrie canònica i que el compilador de l'antígraf $A$ ' va esmenar el seu text gràcies a alguna font externa a la tradició canònica. Certament, no va esmenar la cançó 3 dins la sèrie 1-7 $\left(A^{2}\right)$, però, sortosament, potser gràcies a la diferència d'íncipit, en va copiar un text alternatiu amb la lliçó correcta $\left(A^{1}\right)$.

Les esmenes a posteriori de $L$ en el poema 2 i sobretot en el 7 (v. 40) suggereixen proximitat física entre $A\left(\mathrm{o} A^{\prime}\right)$ i la mà correctora de $L$. Tots dos cançoners degueren circular pels mateixos ambients.

\subsection{El poema 45}

El gran poema de teoria amorosa "Los ignorants Amor e sos exemples» (45), en cent versos estramps, clou actualment el cançoner $L$, però truncat després del vers 40 per una mutilació d'un o més quaderns al final del còdex. Per als versos 41-100 només ens resta $A$ com a únic testimoni hipotètic de $\lambda$ en absència de $L M$ : això vol dir que els possibles errors de $\lambda$ apareixeran com a errors singulars de $A$, i no es podran distingir de les innovacions o dels errors comesos singularment per $A$ o el seu antígraf $A$ '. No obstant això, caldria esperar que el text de $A$ presentés almenys alguna prova d'afinitat amb el grup $\beta$, representat principalment per $N$, en oposició a $F$. El poema manca en $G_{1} \mathrm{i}$ també en $H$, per pèrdua de folis; tenint en compte que $H$ presenta nombroses variants peculiars, sovint recollides per $D G_{2}$, i que de vegades coincideix amb $L$ o $A L$, convé de tenir molt en compte les variants de $D G_{2}$.

En el cançoner $A$, la sèrie 45, 55, 54 apareix precedida de la cançó «Un sobrespler» de Jaume March i seguida de la primera versió del poema «Alt e amor» (3) d'Ausiàs March, del fragment de Lluís de Vila-rasa atribuït a Ausiàs March i del poema «Las, treballat» de Jaume March, amb què es clou el tercer quadern (f. 48v). En un context tan heterogeni, cal considerar la possibilitat que els poemes 45, 55 i 54 davallessin d'una tradició diferent de $\lambda$.

REVISTA VALENCIANA DE FILOLOGIA / I (20I7) p. 6I-94

FRANCESC J. GÓMEZ

Una antologia marquiana a la Barcelona del tercer quart del segle XV / 86 
Atesa l'extensió del poema 45, en podem analitzar per separat els v. 1-40, conservats en $L$, i els v. 41-100, sense el seu testimoniatge.

Poema 45.1-40 (manquen $H M G_{1}$ ). El resultat és anàleg al dels poemes 1,2 i 6 . No hi ha errors que confirmin absolutament el parentiu entre $A L$, mentre que en dos casos poc rellevants i no separatius (v. 7 i 14) $A$ sembla llegir correctament amb $F$ contra $L N$ (són els únics indicis de relació amb $\beta$ ). A presenta sobretot nombroses variants singulars (v. 8, $11,25,26,40$ ) o només compartides amb els testimonis $D G_{2}$ (v. 24 i 37)

Aquests dos casos, relatius a l'amor del cos en contrast amb l'amor de l'ànima, són especialment remarcables. En primer lloc, la substància fonètica dels mots rima de $A D G_{2}$ (v. 24, «lliura»; v. 37, «munte») és més rica i més pròpia dels versos estramps que no pas les lliçons alternatives, força més banals («posa» $\mathrm{i}$ «puge»); a més a més, el mot rima del v. 37 («en grau delitós munte») es retroba en un context molt semblant en el poema teòric 87 , que encapçala la segona secció marquiana de $A$ (v. 207-208: «Amor a mi en delitós grau munta / quan dos lligams arma i cos han a estrènyer»). En segon lloc, els v. 24 i 37 de $A D G_{2}$ proposen una lectura coherent de tot el passatge, remarcant la centralitat del cos en l'amor delitable, mentre que les variants alternatives n'atenuen l'aspecte carnal i en subratllen la natura composta, sota el govern de la voluntat. Aquestes variants de $A D G_{2}$ resulten tan admissibles com les altres i són retòricament més reeixides. És clar que podrien ésser dues felices innovacions d'un poeta profundament ausiasmarquista, però, com en el cas del poema 1, ens convé de tenir en compte la possible influència d'una tradició que no remunti a l'arquetip del corpus canònic, i també el fet que ens manca el testimoni de $H$ i $G_{1}$.

3 perquè-m trasport en altre $N F B D]$ traspost $A L K G_{2}$

7 descreen mort ésser de grat suferta $A F B D G_{2}$ ] de grat ésser $L N K$

8 e que en dolor d'amor delit se mescle $L N F B K D G_{2}$ ] que en gran $A$

11 ira dins pau, e turment molt alegre $L N F B K D G_{2}$ ] turment és $A$

14 Amor dins ells alloga $A F B D G_{2}$ ] allega $L N K$

18 separables $A L N F B K$ : invencibles $D G_{2}$

$24 \mathrm{i}$ en son voler son decret l'arma posa $L N F B K$ : ans al seu [cec

$D G_{2}$ ] foc complidament se lliura $A D G_{2}$

REVISTA VALENCIANA DE FILOLOGIA / I (20I7) p. 6I-94

FRANCESC J. GÓMEZ

Una antologia marquiana a la Barcelona del tercer quart del segle XV / 87 
25 Aquella amor que s (qui·s $N$ ) diu voluntat bona $\left.L N F B K D G_{2}\right]$ qui és $A$

26 esguarda $L N F B K D$ : reguarda $A$ : resguarda $G_{2}$

31 ma arma e cos per ell prenen ses armes $A L N F B K$ : Menys de saber [sentir $G_{2}$ ] dins mi aport ses armes $D G_{2}$

37 Mes perquè en grau (grau om. $L$ ) delitós l'amant puge $L N F B K$ :

Mes perquè.l cos en grau delitós munte $A D G_{2}$

40 són desijats $L N F K D G_{2}$ : són desijants $A: B$ innova

Poema 45.41-100 (manquen $H L M G_{1}$ ). El testimoni $A$ continua

presentant molts errors o innovacions singulars (v. 45, 62, 69, 70, 71, etc.), però aquí no podem comparar amb $L$ per a esbrinar si n’hi ha cap d'heretat d'un antecedent comú.

$D G_{2}$ (en absència de $H$ ) presenten, com de costum, variants peculiars (v. 64, 89, 94, 100), però el fet més destacable és que $A$ hi coincideix totalment (v. 63) o parcialment (v. 58) en possibles innovacions o errors.

En el v. $94 A N B K$ llegeixen contra $F$, mentre que $D G 2$ ofereixen una innovació que afecta tot el vers. Els editors han acollit la lliçó de $F$, sens dubte coherent (v. 93-94):

e cossos dos amb una arma governes

per la virtut que d'amistat s'engendra!

Però la variant "pel gran delit» no és pas un error mecànic. Ben mirat, sembla evocar l'íncipit de la cançó 3 «Alt e amor d'on gran desig s'engendra» amb el canvi de «delit» per «desig». D'altra banda, tenint en compte que March acaba d'evocar Dante (v. 89-90: «Oh bona amor, a qui mort no triümfa, / segons lo Dant història recompta»), cal observar que els versos més memorables de Francesca (Inf. V, 103-105: «Amor, ch'a nullo amato amar perdona / mi prese del costui piacer sí forte / che, come vedi, ancor non m'abbandona») podrien haver inspirat la lliçó «delit» de ANBK. És possible que es tracti d'una lliçó autèntica? Si es tracta, però, d'una altra innovació, cal remarcar que no és exclusiva de $A$, sinó pròpia del grup $\beta$ (en absència de $L$ ).

45 Qui vol trobar amor qui null temps folgue $N F K D G_{2}$ ] cansa $A$ : falga $B$

REVISTA VALENCIANA DE FILOLOGIA / I (20I7) p. 6I-94

FRANCESC J. GÓMEZ

Una antologia marquiana a la Barcelona del tercer quart del segle XV / 88 
58 prop de forçat $N F B K]$ és mig $A G_{2}$ : quasi $D$; és entre ells lo complaure $A N F B K]$ aquests abdós $G_{2}$ : és aquests dos $D$

62 e de aquell tots los actes que n'ixen $N F B K D G_{2}$ ] e d'aquell tots los actes bons $A$

63 mas los volers que d'aquests composts naixen NFBK] Les voluntats $A D G_{2}$ 64 són més punyents $A N F B K]$ ardents $D G_{2}$

89 Oh bona amor $A N F B K]$ tu $D G_{2}$ 94 per la virtut que d'amistat s'engendra $F]$ pel (per $N$ ) gran delit $A N B K$ : La vida llur en un esperit penja $D G_{2}$ 100 natural ignorança $A N F B K]$ general $D G_{2}$

L'escrutini de les variants del poema 45 no aporta proves evidents que $\lambda$ inclogués aquest poema, però $L$ llegeix bàsicament amb $N$ i també hem trobat alguna variant significativa (v. 94) que podria vincular $A$ amb $\beta$ en absència de $L$. Ara bé: com en els poemes 1, 2, 6 i 7, hem constatat en $A$ nombroses variants singulars o compartides amb $D G_{2}$ (v. 24, 37, 63), algunes de les quals sorprenen per la seva qualitat. Tot indica, a parer meu, que el poema 45 podia figurar en l'antologia $\lambda$ amb variants pròpies de la família $\beta$, però que el compilador de l'antígraf $A$ ' també en posseïa un altre testimoni que podem vincular a $D G_{2}$ (en absència de $H$ ).

\section{Un cercle definit de producció, transmissió i conservació}

Una llacuna de vuit cobles i una tornada $(30,17-60 ; 26,1-24)$ en el testimoni $A$ i en el seu apògraf $I$, deguda probablement al salt d'un foli en la còpia dels poemes 30 i 26, fa pensar que $A$ és la còpia no reordenada d'un antígraf $A^{\prime}$ que contenia les obres de March si fa no fa en la mateixa disposició aparentment caòtica que presenten en $A$. D'altra banda, tenim indicis per a pensar que el compilador de $A^{\prime}$ no fou bàsicament responsable de la selecció, sinó sobretot de la disposició, dels poemes inclosos en el seu cançoner marquià. Tot indica que el testimoni $A$ transmet fonamentalment una antologia marquiana preexis-

REVISTA VALENCIANA DE FILOLOGIA / I (20I7) p. 6I-94

FRANCESC J. GÓMEZ

Una antologia marquiana a la Barcelona del tercer quart del segle XV / 89 
tent $(\lambda)$, que $A^{\prime}$ reordenà $i$, potser, també amplià i contaminà amb altres fonts (com també ho pogué fer puntualment el copista de $A$ ). Aquesta antologia $\lambda$ també es transmet, truncada, en el cançoner $L$.

Els vint-i-dos poemes d'Ausiàs March conservats en el testimoni $L$ (6 $\ldots 7 \ldots 1,2 \ldots 3,5,9,11,14,16,17,19,21,27,28,29,33,34,36,37$, $44,45)$ es retroben tots en el testimoni $A$. Divuit d'aquests poemes (3-45) configuren una sèrie saltuària, conforme a l'ordre canònic, que fou copiada a posteriori al final del cançoner $L$. Entre la setantena de poemes marquians inclosos en el cançoner $A$ es retroba exactament la mateixa successió de poemes, encara que repartits en diversos segments i, de vegades, en un ordre invers. L'escrutini de les variants ens confirma que almenys aquests divuit poemes formaven part d'una antologia elaborada a partir d'un manuscrit emparentat amb el grup NBK. Podem postular, doncs, l'existència d'una família $\beta$ integrada per $\lambda$ i $N B K$.

És probable que la sèrie saltuària del testimoni $L$, truncada per la pèrdua d'almenys un quadern després del vers 40 del poema 45, continués fins als darrers poemes transmesos pels testimonis més antics de la poesia de March. El testimoni $A$ conté diversos segments saltuaris de poemes, en successió canònica recta o inversa, amb numeració compresa entre el 45 i el 100. Caldria contrastar ecdòticament la possibilitat que aquests segments també formessin part de l'antologia $\lambda$, com també estudiar l'origen d'una dotzena de poemes de numeració inferior al $45(23,38,13,39,18,42,32,30,26,24,10,31)$ que tanquen el corpus marquià de $A$ i que podrien provenir d'un model diferent de $\lambda$. Així mateix, resten per estudiar les raons compilatòries que provocaren la segmentació de $\lambda$ en el testimoni $A$.

El cançoner de l'Ateneu $(M)$ comparteix els errors de $\lambda$ i $\beta$ en l'esparsa 29 (v. 1, 6, 8). A part de tres esparses $(80,29,81)$ i del maldit 42 , les úniques composicions marquianes copiades en $M$ són les cançons 6 i 7 , la primera afegida clarament a posteriori en un quadern heterogeni i la segona integrada en una secció miscel-lània vagament temàtica. El testimoni $A$ conté els poemes 1-7 en successió canònica recta. En $L$ manca el poema 4, mentre que els poemes 6, 7 i 1-2 no apareixen en la sèrie final, sinó dins el nucli inicial del cançoner —una

REVISTA VALENCIANA DE FILOLOGIA / I (20I7) p. 6I-94 FRANCESC J. GÓMEZ

Una antologia marquiana a la Barcelona del tercer quart del segle XV / 90 
miscel-lània de poetes dels segles XIV i XV—, i, a parer meu, no pas copiats $a$ posteriori aprofitant espais en blanc. L'escrutini de les variants demostra absolutament que $M$ comparteix un antecedent comú amb $L$, potser l'antígraf de $L$ ', en els poemes 6 i 7. No obstant això, no podem assegurar que l'antologia $\lambda$ contingués la sèrie 1-7, especialment el poema 7 . Només es recull algun indici clar d'afinitat amb $\beta$ en la cançó 5, com ja hem dit. En les cançons 2 i 6, $L$ sol coincidir alhora amb $\mathrm{N}$ i amb $D G_{2}$, i $A$ se separa clarament de $L N$ en dos casos $(6,4 ; 2,9)$. Cal tenir, doncs, en compte una possible confluència de dues o diverses tradicions, tant a l'altura de l'antecedent comú a $A L M$ com en la compilació, força complexa, de $A$ '.

En el poema 7 es verifiquen nombrosos errors comuns de $A L M$ i, fins $\mathrm{i}$ tot, tres errors comuns de $A L M$ amb $H D G_{2}$ (v. 16, 21, 65), però cap error comú amb $N$. Els únics errors amb $N$ en el poema 6 (v. 4) també són presents en $D G_{2}$ (en absència de $H$ ). Sembla que en el cas dels poemes 6 i 7 ALM podrien davallar d'un antecedent comú però diferent de $\lambda$, i això podria explicar tant la presència dels poemes 6 i 7 en $M$ com el lloc particular que ocupen en $L$. Si la llacuna del poema 7 (47 e [ ] adeu $\left.A^{a c} I^{a c} L M\right)$ davallava d'aquest antecedent comú, i els compiladors i copistes dels cançoners no foren capaços d'esmenar-la tot i disposar de l'antologia $\lambda$, podem sospitar que el poema 7 no en formava part.

La doble versió del poema 3 en el testimoni $A$, les bones lliçons singulars de $A$ en el poema $1 \mathrm{i}$ les difraccions freqüents entre $A$ i $L$ en el poema 2 (amb correccions a posteriori de $L$ ) també són indici d'un accés a fonts diferents de la branca $\beta$, però considero que no convé precipitar-se a treure'n conclusions sobre la filiació sense haver completat l'estudi dels poemes marquians continguts en $A$.

La varia lectio del poema 45 mena a conclusions similars: probablement formava part de $\lambda$, però el compilador de l'antígraf $A$ ' en devia posseir un altre testimoni que podem vincular a $D G_{2}$ (en absència de $H$ ).

Tot plegat ens obliga a considerar una possible relació entre $A L M$ i el cançoner de Saragossa $(H)$, perquè el comportament d'aquest testimoni és intrigant, malgrat els vincles amb $F G_{1}$ (família $\alpha$ ) que li atribueixen els stemmata

REVISTA VALENCIANA DE FILOLOGIA / I (20I7) p. 6I-94

FRANCESC J. GÓMEZ

Una antologia marquiana a la Barcelona del tercer quart del segle XV / 9I 
de Pagès i Archer. ${ }^{7}$ Malauradament, la pèrdua de molts folis ens priva molt sovint del seu testimoniatge. Allí on en disposem (7, 9-68; 9, 25-44; 11; 14; $16 ; 17 ; 21 ; 27 ; 29 ; 37 ; 44)$ podem constatar que $H$ coincideix força sovint amb $F$, però no pas en errors conjuntius, sinó en lliçons presumiblement correctes, cosa que no demostra la seva pertinença a la família $\alpha$. El que sí que és cert és que $H$ no comparteix els errors comuns de $\beta(A L N B K)$ en els poemes 11 (v. 2), 17 (v. 26), 29 (v. 1, 6, 8), 37 (v. 22) i 44 (v. 11); per tant, hem recollit prou dades per a afirmar que $H$ no davalla de l'antecedent comú a $\lambda$ i $N B K$, però no pas per a concloure que $H$ i $F$ comparteixin una branca de l'arbre textual. De fet, $H$ presenta un nombre molt elevat de variants singulars o bé recollides pels testimonis tardans $D$ i/o $G_{2}$, i, consegüentment, per les edicions del XVI (9, $25 ; 16,40 ; 17,13,16,30,40 ; 21,31 ; 29,3 ; 37,5 ; 44,19)$. D'altra banda, cal tornar a recordar el cas particular del poema 7 , l'únic de la sèrie 1-7 del qual hem conservat el testimoniatge de $H$. Aquest és l'únic poema en què hem trobat possibles errors compartits per $H$ i altres testimonis antics, inesperadament $A L M$ (v. 16, 21, 65), a més de $D G_{2}$.

En el poema 6, en absència de $H$, trobem un error comú de $A L M$ amb $N D G_{2}$ (v. 4); en els poemes 2 i 45, i en la primera cobla del poema 7, també trobem variants comunes de $L$ o de $A$ amb $D G_{2} \cdot{ }^{8}$ Certament, és impossible endevinar les lliçons de $H$ en els textos que n'hem perdut, tot i que és molt probable que algunes de les nombroses variants comunes de $D G_{2}(7,3 ; 28,11,16$; $19,10,11,26,30 ; 28,11,16 ; 33,20,23,24,40 ; 45,18,31,58,64,89,94$, $100)$ també fossin lliçons de $H$. De moment, convé de resignar-se a la incertesa.

7 El testimoni $G_{1}$ només conté sis dels poemes que hem estudiat $(4,5,6,36,37$ i 44), gairebé sempre llegint correctament - per tant, coincidint amb $\mathrm{F}$ - o presentant algun error singular escadusser, però no pas cap error conjuntiu amb $F$. En rigor, només hi podem atribuir un error comú amb $D G_{2}$ en absència de $H$ a 6, 51 (flac] franc). En aquesta mostra, fóra l'únic indici de relació amb testimonis afins a $H$. 8 En la cobla inicial del poema 7, perduda en $H, D G_{2}$ comparteixen errors amb $L M$ en els v. 7 i 8 , mentre que $A$ llegeix amb els altres testimonis. Per contra, en el poema $45 \mathrm{~A}$ llegeix amb $D G_{2}$ contra la resta de la tradició antiga (incloent-hi $L$ ) en els v. 24 i 36 i (en absència de $L$ ) en el v. 63; però el fet més sorprenent és la riquesa dels rims estramps dels dos primers casos (24 posa] lliura $A D G_{2}$; 37 puge] munte $A D G_{2}$ ), perquè, si no són genuïns, són innovació d'un poeta dotat i conscient. Són dades que cal tenir en compte en recerques futures sobre $A$.

REVISTA VALENCIANA DE FILOLOGIA / I (20I7) p. 6I-94

FRANCESC J. GÓMEZ

Una antologia marquiana a la Barcelona del tercer quart del segle XV / 92 
Tot i que no posseïm elements per a datar l'antologia $\lambda$, és evident que circulà durant la dècada dels seixanta i que fou extreta d'un model molt primerenc, probablement en relació amb la reactivació poètica i el culte ausiasmarquista que propiciaren a Catalunya primer la cort del lloctinent Joan de Navarra (1455/1456) i després la del príncep Carles de Viana (1460-1461). Els testimonis $A L M$ formen part de cançoners miscel-lanis $(J L N)$ constituïts després de 1461 a partir d'un conjunt bàsic de materials compartits per tots tres, és a saber, una miscel-lània de poetes dels segles XIV i Xv, un cançoner selectiu de Joan Berenguer de Masdovelles i un conjunt d'obres d'Ausiàs March, aplegades probablement a partir de models diversos: poemes emparentats amb la secció marquiana $H$ del cançoner de Saragossa, i potser d'altres de transmissió extravagant, als quals s'afegí una antologia saltuària conforme a l'ordre canònic $(\lambda)$ emparentada amb la secció marquiana $N$ del cançoner de Nova York. El cançoner de Saragossa fou compilat probablement entre 1461 i 1462 per un cortesà del príncep Carles vinculat a Lleida; el cançoner de Nova York fou potser encarregat i parcialment copiat pel poeta tarragoní Lluís d'Avinyó - uixer d'armes del príncep Carles, que l'havia adobat a cavaller la diada de Sant Joan de 1461— poc abans de la seva mort, entre 1476 i 1477.

Fou durant la segona meitat de la dècada dels cinquanta que els poetes barcelonins Joan Fogassot i Antoni Vallmanya, tots dos notaris, entraren al servei de la cort de Joan de Navarra. El cançoner de l'Ateneu N (March: $M$ ) incorpora dos quaderns heterogenis procedents de la cort del príncep Carles i s'ha relacionat amb Joan Fogassot. El cançoner de París $J$ (March: A) i el seu apògraf $K$ (March: $I$ ) són testimoni únic de les poesies de «mossèn Avinyó» —a part de les del Cancionero de Vindel, potser compilat per Avinyó mateix-, alhora que hi ha indicis per a relacionar-los amb Antoni Vallmanya i per a creure que $J$ tingué un propietari pròxim a Fogassot $\mathrm{i}$ al consistori poètic de Barcelona pels volts de 1475. Algunes esmenes a posteriori en els poemes 2 i 7 del cançoner $L$ (esp. 7, 40) indiquen proximitat física amb $J(A)$ o amb el seu antígraf $\left(A^{\prime}\right)$. La numeració en xifres aràbigues dels poemes de March en els cançoners $J$ $(A)$ i $K(I)$ demostren una proximitat encara més estreta i perdurable.

REVISTA VALENCIANA DE FILOLOGIA / I (20I7) p. 6I-94

FRANCESC J. GÓMEZ

Una antologia marquiana a la Barcelona del tercer quart del segle XV / 93 
En conjunt, les vicissituds de l'antologia $\lambda$, la confluència de tradicions que s'entreveu en les miscel-lànies barcelonines i la fortuna posterior d'aquestes cançoners revelen la intensitat creixent del culte ausiasmarquista a l'entorn d'un nucli barceloní molt cohesionat i interessat en la transmissió i la conservació del llegat poètic català del segle Xv.

\section{Bibliografia}

Alberni, A.; Badia, L.; Cabré, L. (ed.) (2010) Translatar i transferir: la transmissió dels textos i el saber (1200-1500), Santa Coloma de Queralt, Obrador Edèndum / Universitat Rovira i Virgili.

Archer, R. (ed.) (1997) Ausiàs March, Obra completa, Barcelona, Barcanova, 2 vol.

Beltran, V. (ed.) (2006a) El cançoner de Joan Berenguer de Masdovelles, Barcelona, PAM.

- (2006b) Poesia, escriptura i societat: els camins de March, Castelló de la Plana / Barcelona, Fundació Germà Colón Domènech / PAM.

Bohigas, P. (ed.) (1952-1959) Ausiàs March, Poesies, Barcelona, Barcino, 5 vol.

CABré, L.; Turró, J. (1995) «Perché alcun ordine gli habbia ad esser necessario: la poesia 1 d'Ausiàs March i la tradició petrarquista", Cultura Neolatina 55, p. 117-136.

CABré, M. (2002) «Jutges, processos i sentències en la lírica del xv: Joan Ramon Ferrer, mantenidor del gai saber (1475)» Estudi General 22, p. 409-420.

Galí, M.; Ramos, R.; Torró, J. (2010) «De mossèn Avinyó a Lluís d'Avinyó, uixer del príncep de Viana», dins Alberni, Badia \& Cabré (2010), p. 475-508.

Marfany, M. (2007) «D’Ausiàs March a Bernat Hug de Rocabertí: Antoni Vallmanya i el cànon poètic de mitjan segle XV», Llengua \& Literatura 18, p. 45-73.

- (2010) «La traducció catalana medieval de La Belle dame sans merci d'Alain Chartier», dins Alberni, Badia \& Cabré (2010), p. 179-188.

PAGÈs, A. (1912-1914) Les obres d'Auzias March, Barcelona, IEC, 2 vol.

Ramos, R.; Rodríguez Risquete, F. J.; Torró, J. (2014) «Mossèn Avinyó, the Cancionero de Vindel and the Cançoner llemosí del siglo XV», Digital Philology 3, núm. 1 (Primavera), p. 142-161.

Rodríguez Risquete, F. J. (2003) Vida y obra de Pere Torroella, tesi doctoral, Girona, Universitat de Girona, 2 vol.

_ (2010) «El Cançoner de l'Ateneu (Biblioteca de l'Ateneu de Barcelona, ms. 1)», dins Alberni, Badia \& Cabré (2010), p. 425-473.

Torró Torrent, J. (2010) «El Cançoner de Saragossa», dins Alberni, Badia \& Cabré (2010), p. 379-423.

REVISTA VALENCIANA DE FILOLOGIA / I (20I7) p. 6I-94

FRANCESC J. GÓMEZ

Una antologia marquiana a la Barcelona del tercer quart del segle XV/94 